\title{
Report on paediatric care in the Moroccan military mission in the Gaza Strip
}

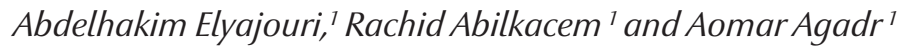

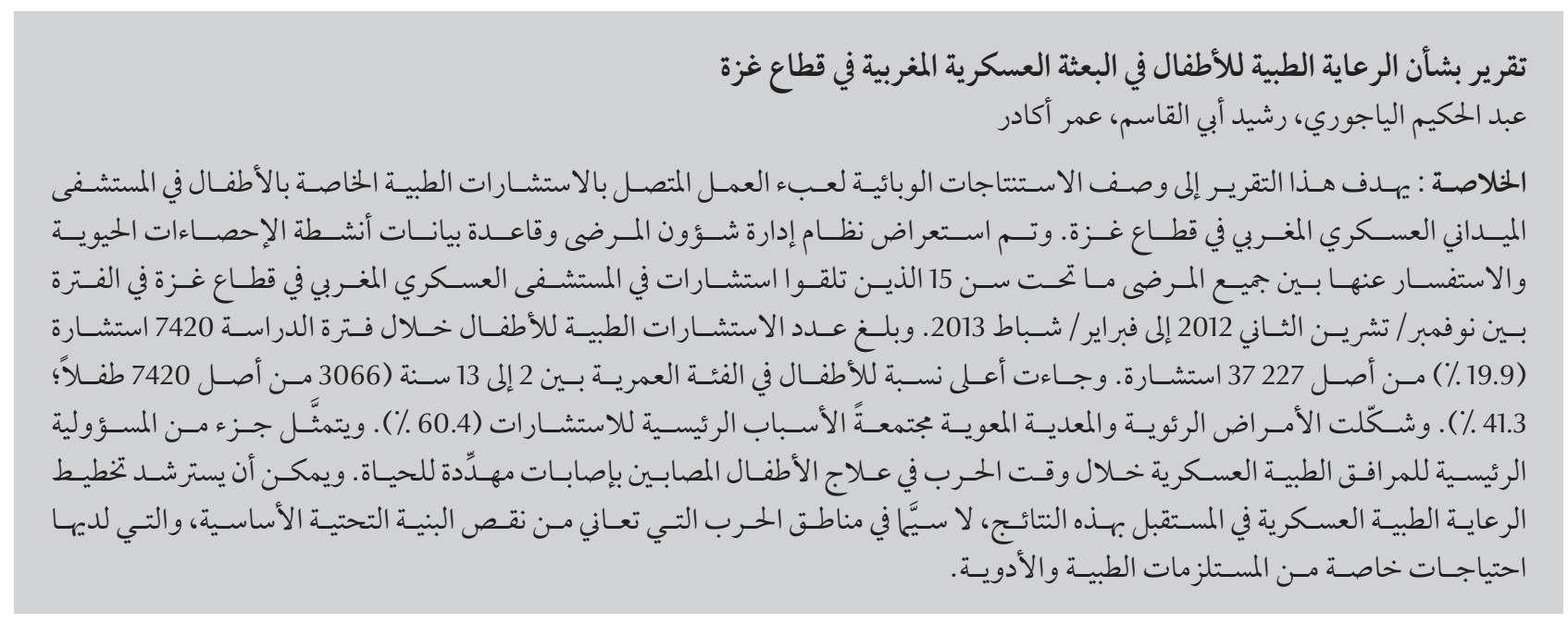

ABSTRACT This report aims to describe the epidemiologic findings of the workload associated with paediatric consultation of the Moroccan Military field hospital in the Gaza Strip. The patient Administration System and Biostatistics Activity database was reviewed and queried for all patients $<15$ years of age who were consulted in the Moroccan Army hospital in the Gaza Strip between November 2012 to February 2013. Paediatric consultations during the study period were 7420 (19.9\%) out of 37227 consultations. The largest proportion of children were from 2 to 13 years old (3066 of 7420 children; $41.3 \%)$. Combined, pulmonary and gastroenterology diseases were the main causes for consultations (60.4\%). Paediatric patients with threatening life injuries form part of the primary responsibility of military medical facilities during wartime. The findings may guide future military medical care planning, particularly in war zones suffering a lack of basic infrastructure, with special a need for medical supplies and drugs.

\section{Rapport sur les soins pédiatriques pendant la mission militaire marocaine dans la Bande de Gaza}

RÉSUMÉ Le présent rapport a pour objectif de décrire les résultats épidémiologiques découlant de l'étude de la charge de travail associée aux consultations pédiatriques de l'hôpital de campagne militaire marocain dans la Bande de Gaza. La base de données consacrée à l'administration des patients et à l'activité biostatistique a été interrogée pour l'ensemble des patients de moins de 15 ans qui avaient consulté à l'hôpital de campagne militaire marocain dans la Bande de Gaza entre novembre 2012 et février 2013 et les données obtenues ont été passées en revue. Les consultations pédiatriques durant la période de l'étude étaient au nombre de 7420 (19,9\%) sur 37227 consultations. La plus grande proportion d'enfants avait entre 2 et 13 ans (3066 enfants sur 7420, soit 41,3\%). Les causes principales de consultation étaient les maladies pulmonaires et gastro-entérologiques cumulées $(60,4 \%)$. Les patients pédiatriques souffrant de traumatismes potentiellement fatals constituent une partie de la responsabilité première des établissements de santé militaires en temps de guerre. Les résultats pourraient orienter la planification des soins médicaux à l'avenir, en particulier dans les zones de guerre souffrant d'un manque d'infrastructures de base, avec un besoin spécial en fournitures médicales et en médicaments. 


\section{Introduction}

On 14 November 2012 the Israeli army launched the largest military attack recorded since 2009, Operation Pillar. According to a report from the UN Office of Humanitarian Affairs, many civilians were wounded on both sides: 160 Palestinians were killed, among them 33 children, 13 women and 3 journalists, while 4 Israeli civilians and 2 soldiers were killed (1).

The rationale behind setting up the Moroccan military field hospital in the Gaza Strip was to provide medical assistance to the Palestinian people affected by the conflict and to complement existing medical structures. The Moroccan field hospital is a medical-surgical hospital, equipped with specialized medical units of the Royal Armed Forces and Moroccan civilian physicians and paramedics. Paediatric care consisted of providing patients with general physical examination, primary treatment, thoracic radiography, drugs/medication, diapers and milk free of charge.

In war zones such as the Gaza Strip, children are the most vulnerable, and often account for the heaviest losses in numbers of dead and injured and in psychological damage. In view of the importance of measuring the extent of such situations, this report aims to inform on the number of cases of each condition diagnosed, detailed by age and sex, which will help in predicting needs for any interventions in future missions.

It should be noted that in 2012 a similar humanitarian initiative was carried out in Jordan, the Moroccan field hospital in the Zaatari refugee camp $(2,3)$.

\section{Methods}

We carried out a descriptive qualitative study based on the patient administration system and biostatistics activity database that was reviewed for all patients $\leq 15$ years of age who attended the Moroccan army field hospital in the Gaza Strip between November 2012 to February 2013. The hospital was deployed 48 hours after the start of the ceasefire between Palestinian organizations and Israel.

During the mission, data on all patients who attended the military field hospital during the study period were recorded in a database maintained by an agent of the Patient Administration Systems and Biostatistics Activity. This held information on all patients aged $\leq 15$ years who attended the hospital. The database was reviewed each day by the doctor responsible for the accurate registry of data. All relevant information on the patients gathered in the consultation and in conversation with the parents was reported. This was summarized at the end of each day and recorded in the database by the agent responsible and double-checked by the consulting doctor.

Prior to any admission, the patients and/or their parents were asked if they would consent to sharing information anonymously on age, sex, date of examination and diagnosis and answers to questions relevant to the diagnosis. All patients agreed to the request.

In order to represent the epidemiological profile in the Gaza Strip, and more specifically the patients attending the Moroccan military field hospital during the period of the mission, all the patients aged $\leq 15$ years $(7420)$ were considered as the population of the current study. This profile was compiled using spreadsheet data summary (MS Excel, 2016), and designed as a descriptive and quantitative study. This study is a retrospective one, conducted over a 70-day period from November 2012 to February 2013, covering all children admitted in the paediatric unit. However, psychiatric diseases and paediatric surgery were beyond the scope of the study.

All ethical considerations were taken into account (respect of persons, benefit of the patients and justice).

\section{Results}

A total of 37227 patients consulted the field hospital, of whom 7420 (19.9\%) were children aged $\leq 15$ years. Our data for each patient documented age, sex and diagnosis. More than half the patients were female, 3952 (56.1\%), a sex ratio of 1:0.71. The median age was 3 years; $15.1 \%$ were aged under 28 days, $30.6 \%$ were aged 28 days to $<2$ years, $41.3 \%$ were 2 to $<13$ years, while 794 (13.0\%) were adolescents ( $13-15$ years old) (Table 1).

Most of the children admitted had pulmonary diseases (37.4\%), mainly influenza-like illness (67.0\%), with $20.0 \%$ having infections of lower respiratory tract. Asthma and broncholaveolitis accounted for 5\% each, while the rest was admitted for allergic rhinitis (Table 2).

Nearly a quarter of admission were for gastroenterology (23.1\%), with around half of these affected by parasitic infections and intestinal worms

Table 1 Age range in of the paediatric patients attending the Moroccan military hospital deployed in the Gaza Strip $(n=7420)$, November 2012-February 2013

\begin{tabular}{lrrrc}
\hline Age & Males & Females & \multicolumn{2}{c}{ Total } \\
& & & No. & $\%$ \\
\hline$<28$ days & 398 & 722 & 1120 & 15.1 \\
28 days-<2 years & 907 & 1363 & 2270 & 30.6 \\
$2-<13$ years & 1472 & 1594 & 3066 & 41.3 \\
13-15 years & 300 & 664 & 964 & 13.0 \\
Total & 3077 & 4343 & 7420 & \\
\hline
\end{tabular}




\begin{tabular}{|c|c|c|}
\hline Specialty/diagnosis & No. & $\%$ \\
\hline Pulmonology & 2777 & $37.4^{\mathrm{a}}$ \\
\hline Influenza-like illness & 1861 & 67.0 \\
\hline Lower respiratory tract infection & 555 & 20.0 \\
\hline Asthma & 149 & 5.4 \\
\hline Bronchoalveolitis & 139 & 5.0 \\
\hline Allergic rhinitis & 73 & 2.6 \\
\hline Gastro-Enterology & 1707 & $23.1^{\mathrm{a}}$ \\
\hline Gastroenteritis/diarrhoea & 327 & 19.2 \\
\hline Parasitic infections/intestinal worms & 827 & 48.4 \\
\hline Oxyuriasis 591 (71.0\%) & & \\
\hline Amoebiasis 169 (20.0\%) & & \\
\hline Blastocystis hominis $30 \quad$ (4.0\%) & & \\
\hline Endolimax nana $17 \quad$ (2.0\%) & & \\
\hline Ascariasis $\quad 9 \quad(1.0 \%)$ & & \\
\hline Giardiasis $\quad 8 \quad(1.0 \%)$ & & \\
\hline Taenia saginata $3 \quad(<1.0 \%)$ & & \\
\hline Colic & 301 & 17.6 \\
\hline Gastroesophageal reflux disease (GERD) & 157 & 9.2 \\
\hline Low weight & 39 & 2.3 \\
\hline Hepatitis A & 30 & 1.8 \\
\hline Constipation & 26 & 1.5 \\
\hline Ear, nose \& throat & 1201 & $16.2^{\mathrm{a}}$ \\
\hline Angina-pharyngitis & 793 & 66.0 \\
\hline Sinusitis & 240 & 20.0 \\
\hline Otitis & 108 & 9.0 \\
\hline Mumps & 60 & 5.0 \\
\hline Neonatology & 608 & $8.2^{\mathrm{a}}$ \\
\hline Colic & 300 & 49.3 \\
\hline Neonatal infection & 193 & 31.7 \\
\hline Jaundice & 79 & 13 \\
\hline Excessive parental anxiety & 36 & 5.9 \\
\hline Dermatology & 426 & $5.7^{\mathrm{a}}$ \\
\hline Diaper rash & 236 & 55.4 \\
\hline Eruptive fever & 91 & 21.4 \\
\hline Scabies & 59 & 13.8 \\
\hline Acne & 29 & 6.9 \\
\hline Alopecia & 11 & 2.6 \\
\hline Nephrology & 405 & $5.5^{\mathrm{a}}$ \\
\hline Urinary tract infection & 174 & 43.0 \\
\hline Enuresis & 231 & 57.0 \\
\hline Neurology & 136 & $1.8^{\mathrm{a}}$ \\
\hline Febrile convulsion & 51 & 37.5 \\
\hline Meningitis (suspicion) & 32 & 23.5 \\
\hline Epilepsy & 26 & 19.1 \\
\hline Cerebral palsy & 20 & 14.7 \\
\hline Other (mucopolysaccharidosis, spinal amyotrophy, etc) & 7 & 5.1 \\
\hline Haematology & 115 & $1.5^{\mathrm{a}}$ \\
\hline Anaemia & 115 & 100.0 \\
\hline Other (cardiac, rare diseases) & 45 & $0.6^{\mathrm{a}}$ \\
\hline
\end{tabular}

${ }^{a}$ Calculated from total number of paediatric patients. and around one-fifth diagnosed with gastroenteritis/diarrhoea (Table 2). Oxyuriasis was by far the dominant condition under the parasitic infections and intestinal worms classification, with 591 cases, followed by 169 cases of amoebiasi, and 30 cases of Blastocystis hominis. We found a small number of parasitic coinfections (Table 3 ).

Of the 7420 patients admitted to the hospital, 1201 had ear, nose and throat conditions (16.2\%). Angina-pharyngitis affected two-thirds of the cases and $20.0 \%$ were sinusitis-related (Table 2).

Colic accounted for almost half the neonatological disease cases, while around one-third were attributed to neonatal infection and $13.0 \%$ were for jaundice (Table 2).

Only $5.7 \%$ of the consultations resulted in a diagnosis of dermatologic disease. Half these patients presented with diaper rash, and about a third were diagnosed with eruptive fever (Table 2).

Febrile convulsion were the most common neurologic conditions seen, with $37.5 \%$ of the 136 patients, followed by a $19.1 \%$ presenting with epilepsy. Some 32 cases were suspected meningitis and were transferred to $\mathrm{Al} \mathrm{Quds}$ Hospital (Table 2).

The remaining sets of diagnosis are nephrology, haematology and other diseases with 405, 115 and 45 cases respectively. There was a relatively high demand for milk and diapers: they were asked for in 1 in 5 consultations (1549).

From our conversations with the patients and their parents, we estimated $72 \%$ of the children were experiencing second hand smoking.

\section{Discussion}

Paediatric patients accounted for $19.9 \%$ of all hospital consultations to the military treatment facilities in Gaza strip between November 2012 and February 2013. The most common diagnoses 


\begin{tabular}{lc}
\hline Table 3 Parasitic coinfections identified among paediatric patients attending the \\
Moroccan Military Hospital deployed in the Gaza Strip $(\boldsymbol{n}=\mathbf{7 4 2 0})$, November \\
2012-February 2013 \\
\begin{tabular}{lc} 
Organisms & 3 \\
Entamoeba coli + Blastocystis hominis & 2 \\
Giardia intestinalis + Blastocystis hominis & 2 \\
Entamoeba hystolitica + Giardia intestinalis & 1 \\
Entamoeba hystolitica + Endolimax nana + Blastocystis hominis & \\
\hline
\end{tabular}
\end{tabular}

were for pulmonary and gastroenterology diseases, with high frequencies of influenza-like illness, lower and upper respiratory tract infection and digestive parasitic infections.

It is worth noting that in a similar humanitarian action deployed by the Moroccan Military field Hospital in Zaatari Camp, the epidemiological profile of Syrian refugee children shows dehydration as the primary reason for admission (64\%), followed by urinary infections (15\%) then pulmonary diseases (10\%) (2). In a similar study by Benjelloun et al. in the Zaatari Camp, asthma was the most prevalent disease in males under age 18 years (3).

We are the first humanitarian mission to publish on the epidemiological profile of the Gaza Strip. However, in order to understand the situation and to put our results into perspective, it must be remembered that the Gaza Strip is a very small area of land $\left(360 \mathrm{~km}^{2}\right)$, housing a population of 1.8 million, where $43.2 \%$ are under 14 years old, and the median age is 18.4 years, ranking Gaza as one of the most densely populated places on earth (4). Given that the birth rate is 32.2 births/ 1000 population, a total fertility rate of 4.42 children born/ woman, and the mother's average age at first birth is 19 years old, it is clear that paediatric care is greatly needed.

Passive smoking is an important issue as well in the Gaza Strip. In fact, we estimated $72 \%$ of the children in our sample experienced second hand smoking. Smoking prevalence in Gaza is $13.7 \%$ (5). In Zaatari Refugee Camp, Benjelloun et al. reported $70 \%$ of the pedantic patients who consulted for pulmonary disease were exposed to smoking (3).

One of the results of our analysis shows a high number of cases related to parasitic infections, with an overall Shawa on the prevalence of intestinal parasites in different provinces of Gaza found $20.00 \%$ in Rafah camp, $19.97 \%$ in the mid zone, $18.96 \%$ in Khan Yonis, $17.14 \%$ in the North and a low prevalence in Gaza of $15.05 \%$ (6). In a 2008 study by Abu Amra et al, the total coliform contamination reached $22 \%$ in wells and $25 \%$ in water supplies, exceeding World Health Organization recommendations. Waterborne diseases are frequent because of poor chlorination, and irregular water supply, which is the case for the infrastructure in Gaza (7).

This introduces the quality of the sanitation system infrastructure: a partially functioning wastewater treatment system, an overloaded capacity and no disposal management has led to the use of some coastal sites for waste disposal and landfill $(6,8)$, therefore affecting the sand beach and seawater quality. Gaza beach is the only recreational site in this area, making it a hazard, and a 2005 coliform in sand than in seawater (8).

While some parasitic infections are not pathologic or even clinically evident, a number can lead to significant longterm morbidity or mortality. Examples include hookworm infestation causing severe anaemia and malnutrition; Ascaris infections causing small bowel obstruction; Schistosoma causing periportal hypertension; and Strongyloides causing acute hyperinfection syndrome prevalence of $11.1 \%$. The study by Ala study showed higher levels of fecal in immunosuppressed patients (9). Early detection is key in this vulnerable population to prevent complications as well as to minimize any possible exposure of the greater Gaza public to nonendemic infections.

In 2014, the blockade imposed by the Israeli army on Palestine left at least $21 \%$ of the inhabitants of Gaza in extreme poverty, and led to malnutrition and more restrictions in the trade in goods (10). Additionally, the estimated impact of the 2007-2010 economic blockade was a $30 \%$ loss in welfare and a large decline in labour productivity (11). This partially explains the high demands for milk and diapers, 1549 demands during our military field mission.

Our study is the first to depict the epidemiological profile in the Gaza Strip, and it benefited from the willingness of the Palestinian authorities and people to provide the necessary data for the study. Although, all available paediatric data were used, there is a need for a more comprehensive study and this should include an epidemiological profile of all admissions (adults, other field hospitals, etc.) and go deeper into explaining the patterns observed, if any. The lack of similar published studies on paediatric care in war zones makes it more difficult to reveal patterns.

Marked by a fragile geopolitical setting, very weak infrastructure, and scarce human, financial and technical resources, the situation in Gaza warrants more attention, particularly aimed at children and adolescents. In fact, the high numbers of admissions in the paediatric unit highlight the essential role of paediatricians in war zones and the delicate state of children's health.

Funding: The study itself received no funding. The Moroccan Military Field Hospital in the Gaza Strip was established following the decision of the King of Morocco as a humanitarian initiative funded by the Moroccan Government.

Competing interests: None declared. 


\section{References}

1. UN human rights experts deplore high toll on civilians of Gaza-Israel violence. New York: UN News Centre; 2012 (http://www.un.org/apps/news/story. asp?News $\mid \mathrm{D}=43584 \& \mathrm{Cr}=$ gaza\& $\mathrm{Cr} 1=\#$.ULSiPLon3K1, accessed 27 June 2017).

2. Ayad A, Malih M, Agadr A. SFP PC-27 - Profil épidémiologique des hospitalisations pédiatriques à l'hôpital militaire marocain de campagne du camp de refugiés ZAATARI (Jordanie 2013). Archives de Pédiatrie. 2014;21(5 Suppl. 1):917.

3. Benjelloun A, Zrara A, Jira $M$. Profil épidémiologique de I'asthme à I'hôpital marocain pour les réfugiés syriens du Zaatari, Jordanie. Revue des Maladies Respiratoires. 2015;32(Suppl.):A51.

4. World Factbook. Middle East: Gaza Strip. Washington DC: Central Intelligence Agancy; 2015 (https://www.cia.gov/ library/publications/the-world-factbook/geos/gz.html, accessed 15 June 2015)

5. Reem T. Abu Shomar, Smoking, awareness of smoking-associated health risks, and knowledge of national tobacco legislation in Gaza, Palestine. Cent Eur J Public Health. 2014;22(2):80-9.
6. Al-Shawa R. Intestinal parasites infections in refugees camps in the Gaza governorates, Palestine. Internet J Parasitic Dis. 2006;1(2):1-6.

7. Abu Amra SS, Yassin MM. Microbial contamination of the drinking water distribution system and its impact on human health in Khan Yunis Governorate, Gaza Strip: seven years of monitoring (2000-2006). Public Health. 2008;122:1275-83.

8. Afifi S, Alnahhal S, Abdelall S. Developing an integrated sustainable system for urban areas: Gaza Strip case study. Procedia CIRP. 2015;26:767-74.

9. Mody R. Intestinal parasites. In: Walker PF, Barnett ED, eds. Immigrant medicine, 1st ed. Philadelphia: Elsevier; 2007:273-307.

10. OMS soixante-septième assemblée mondiale de la sante. Situation sanitaire dans le territoire palestinien occupé, y compris Jérusalem-Est, et dans le Golan syrien occupé, Point 19 de I'ordre du jour, 19 mai 2014. Geneva: World Health Organization; 2014.

11. Etkes H, Zimring A. When trade stops: lessons from the Gaza blockade 2007-2010. J Int Econom. 2014;95(1):16-27. 